\title{
PRÁTICAS PEDAGÓGICO-DIDÁTICAS E A SUA INFLUÊNCIA NA CONFIGURAÇÃO DO ESPAÇO ESCOLAR. A MATERIALIDADE DAS ESCOLAS DE ENSINO MÚTUO EM PORTUGAL À LUZ DOS DIRETÓRIOS DO MÉTODO (1835-1844)
}

Pedagogical/ didactic practices and their influences on the configuration of the school spaces. The materiality

of the monitorial schools in Portugal after the method guides (1835-1844)

\section{Prácticas pedagógico-didácticas y su influencia} en la configuración del espacio escolar. La materialidad de las escuelas de enseñanza mutua en Portugal a la luz de los manuales del método (1835-1844)

\section{Carlos Manique da Silva*}

Fecha de recepción: 19/09/2016 • Fecha de aceptación: 03/12/2016

Resumo. Nas primeiras décadas do século XIX o método ou modelo de ensino mútuo gera ampla discussão pedagógica em vários países (a sua difusão transcontinental não tem mesmo precedentes). Não obstante ter passado rapidamente pela paisagem pedagógica, exerce uma influência decisiva na definição de uma organização pedagógica específica para a escola primária pública, levando à superação (irreversível) do ensino individual e à legitimação do ensino simultâneo. Num primeiro momento, à luz de investigação já produzida, procuro contextualizar de que forma se deu em Portugal a receção do método, relevando a pluralização de interpretações dessa tecnologia educativa no curso da sua difusão mundial. Num segundo momento, recorrendo a materiais impressos —no caso, dois diretórios do método redigidos em Portugal (1835 e 1844)— e aos dados neles plas-

\footnotetext{
" Instituto de Educação. Universidade de Lisboa. Alameda da Universidade. 1649-013 Lisboa. Portugal.manique@net.sapo.pt.
}

Cómo citar este artículo: Manique da Silva, Carlos. «Práticas pedagógico-didáticas e a sua influência na configuração do espaço escolar. A materialidade das escolas de ensino mútuo em Portugal à luz dos diretórios do método (1835-1844)», Historia y Memoria de la Educación, 6 (2017): $459-485$ 
mados a respeito da materialidade das escolas (em causa, entres as datas assinaladas, não apenas as mudanças que se observam mas também as continuidades), argumento uma ideia central: a de que as práticas pedagógico-didáticas, se preferirmos, a interação professor / alunos em situação de ensino e de aprendizagem, têm uma influência decisiva na evolução e configuração dos espaços escolares.

Palavras Chave: Circulação do conhecimento pedagógico; Ensino mútuo; Materiais impressos; Materialidade da escola.

Abstract. In the first decades of the nineteenth century the monitorial system of education generated widespread pedagogical discussion in several countries (as well as unprecedented transcontinental diffusion ). Despite having passed quickly through the educational landscape, this model exerted a decisive influence in defining a specific educational organization for public primary schools, one that would prevail (irreversibly) over individual instruction and the legitimization of simultaneous teaching. First of all, in light of research already carried out on the subject, we aim to contextualize the way in which the method was received in Portugal, emphasizing the pluralization of interpretations of this educational technology in the course of its diffusion worldwide. Secondly, using printed materials -in this case, two guides of the method written in Portugal (1835 and 1844) — and the data in them concerning the materiality of schools (taking note, between the given dates, of the changes as well as the continuities), we defend a central idea: that the pedagogical-didactic practices, i.e., the interaction of teacher/students in the teaching and learning situation has a decisive influence on the evolution and configuration of school spaces.

Key words: Pedagogical knowledge circulation; Monitorial system of education; Printed materials; School materiality.

Resumen. En las primeras décadas del siglo XIX el método o modelo de enseñanza mutua generó una amplia discusión pedagógica en varios países (a la vez que una difusión transcontinental sin precedentes). A pesar de su rápido paso por el escenario pedagógico, ejercerá una influencia decisiva en la definición de una organización pedagógica específica para la escuela primaria pública, que condujo a la superación (irreversible) de la enseñanza individual y a la legitimación de la enseñanza simultánea. En un primer momento se procura contextualizar, a la luz de la investigación existente, la forma en que se dio en Portugal la recepción del método, mostrando la pluralidad de interpretaciones de esa tecnología educativa en el curso de su difusión mundial. En un segundo momento, a partir de la revisión de materiales impresos —específicamente dos guías del método redactados en Portugal (1835 y 1844) - y de las informaciones plasmadas en ellos respecto de la materialidad de las escuelas (atendiendo, en las fechas señaladas, a los cam- 
bios y las continuidades operadas), argumento una idea central: la de que las prácticas pedagógico-didácticas —o, si se prefiere, la interacción profesor/alumnos en situación de enseñanza/aprendizaje - tiene una influencia decisiva en la evolución y configuración de los espacios escolares.

Palabras clave: Circulación del conocimiento pedagógico; Enseñanza mutua; Materiales impresos; Materialidad de la escuela.

\section{INTRODUÇÃO}

Alguns autores têm argumentado com a ideia de que o edifício escolar, enquanto espaço especificamente pensado e desenhado para esse fim, reflete um sistema de valores e determinadas noções de pedagogia. ${ }^{1}$ Desse ponto de vista, cada edifício representa "[the] contemporary thought about learning and teaching». ${ }^{2}$ Dito de outro modo, na sua materialidade, os espaços desenhados traduzem a forma como se espera que os professores e os alunos ajam, com que fim ou propósitos e, ao mesmo tempo, que ações estarão inibidas. Mas há uma questão que emerge quando pensamos na influência das caraterísticas do edifício escolar nos processos de ensino e de aprendizagem, que tem sido objeto de investigação para períodos bem recentes da nossa história, nomeadamente, no que diz respeito aos programas de modernização dos espaços escolares: a de saber até que ponto a referida influência se faz sentir. ${ }^{3}$ Segundo estas investigadoras, ${ }^{4}$ que tomam como referência o Programa de Modernização das Escolas de Ensino Secundário, ${ }^{5}$ a renovação de espaços escolares não teve um impacto decisivo nas práticas docentes, as quais «remain[ed] set in a traditional mould». ${ }^{6}$

\footnotetext{
${ }^{1}$ Cf., por exemplo, Antonio Viñao Frago \& Agustín Escolano Benito, Currículo, espaço e subjetividade: a arquitetura como programa (Rio de Janeiro: DP\&A, 2001); Martin Lawn \& Ian Grosvenor, Materialities of schooling: Design, technology, objects, routines (Oxford: Symposium Books, 2005); Catherine Burke \& Ian Grosvenor, School (London: Reaktion Books, 2008); Rita de Cássia Gonçalves, Arquitetura Flexível e Pedagogia Ativa: um (des)encontro nas escolas de espaços abertos (Lisboa: Instituto de Educação da Universidade de Lisboa, 2011).

2 Burke \& Grosvenor, School, 11.

3 Alexandra Duarte, Luísa Veloso \& Joana Marques, "Changing education through learning spaces: impacts of the Portuguese schools buildings' renovation programme», Cambridge Journal of Education, 44 (3), (2014): 401-423.

4 Duarte, Veloso \& Marques, "Changing education through learning spaces».

5 Programa executado em Portugal entre 2007 e 2011; prossegue ainda, mas com muitos entraves.

${ }^{6}$ Duarte, Veloso \& Marques, «Changing education through learning spaces», 418.
} 
Se recuarmos aos anos de 1970-80 - período em que ganha corpo a ideia de que "o edifício faz o método de ensino» - ${ }^{7}$ encontramos um caso que elucida bem a dificuldade em encorajar uma "pedagogia» a partir (dir-se-ia quase em exclusivo) da conceção de novos ambientes educativos. Refiro-me à experiência das escolas de área aberta em Portugal. $\mathrm{Na}$ verdade, o fundamento que presidiu à conceção dessas escolas, ou seja, o de promover a rutura com a organização em classe, foi rejeitado por muitos professores, diretores e, mesmo, encarregados de educação. ${ }^{8}$ Aliás, Catherine Burke e Ian Grosvenor mencionam que a investigação realizada nos Estados Unidos da América na década de 1970 a respeito da conceção dos edifícios escolares - e acrescentam que metade das escolas construídas no final dos anos de 1960 eram de área aberta- aponta para a seguinte conclusão: «architectural design does not fundamentally determine teacher practice, but that teachers determine and arrange their spaces in accordance with their perceived needs, habits and beliefs». ${ }^{9}$

Por outro lado, como sublinham Tondeur, Bruyne, Driessche, McKenney \& Zandvliet, ${ }^{10}$ investigação recente tem demonstrado que as tecnologias de informação e comunicação (TIC) estão a influenciar a organização da sala de aula. Os mencionados investigadores indicam, ainda, que as mudanças na organização espacial também podem estar associadas a mudanças nas práticas pedagógicas. ${ }^{11}$ Mas, a nota dominante, acresce dizer, é a de que o layout da sala de aula tem permanecido muito estável, não obstante o esforço de arquitetos, desenhadores de mobiliário escolar e reformadores educacionais para o ajustarem. ${ }^{12}$

\footnotetext{
7 João Barroso, «Innovation and change in school: challenges to teachers and architects», Education Buildings and Equipment, 28, (2002): 23.

${ }^{8}$ Miguel Martinho \& José Freire da Silva, «Open Plan Schools in Portugal: Failure or Innovation?», PEB Exchange, 12, (2008): 1-9. A este propósito, é também interessante referenciar a opinião dos seguidores de Ovide Decroly, na década de 1940, no sentido em que consideravam que os projetos arquitetónicos inovadores não se traduziriam em «better learning effects as long as the "old" pedagogical-didactic praxis continued to be applied». Frederik Herman, Angelo Van Gorp, Frank Simon, Bruno Vanobbergen \& Marc Depaepe, «Modern architecture meets new education. Renaat Braem's design and the Brussels Decroly school», Revue Belge d'Histoire Contemporaine, XLI, (2011): 150.

${ }^{9}$ Burke \& Grosvenor, School, 152.

10 J. Tondeur, E. de Bruyne, M. Van Den Driessche, S. McKenney \& D. Zandvliet, «The physical placement of classroom technology and its influences on educational practices», Cambridge Journal of Education, 45 (4), (2015): 537-556.

11 Tondeur, de Bryne, Van Den Driessche. McKenney \& Zandvliet, «The physical placement of classroom technology and its influences on educational practices».

${ }^{12}$ Herman, Van Gorp, Simon, Vanobbergen \& Depaepe, «Modern architecture meets new education. Renaat Braem's design and the Brussels Decroly school», 135-166.
} 
Mais do que ver o edifício escolar como indutor de uma determinada «pedagogia» ou capaz de moldar a experiência escolar, no presente texto o meu argumento central é o de que as práticas pedagógico-didáticas, se quisermos, a interação professor / alunos em situação de ensino e de aprendizagem, têm uma influência decisiva na configuração dos espaços escolares. ${ }^{13}$ Nessa linha de pensamento, o que pretendo enfatizar são as mudanças que ocorrem devido a fatores internos. Recorro às palavras de Thomas Markus (e a uma analogia com um espaço litúrgico) para elucidar esta última ideia: "Monasteries were gradually remodelled in response to changes in liturgical practice, the Rule, or the numbers of monks, expanded activities». ${ }^{14}$ Por outras palavras, aquilo que dá sentido aos edifícios é a maneira como são usados e experienciados. ${ }^{15} \mathrm{E}$, à luz da lição de Thomas Markus, há três níveis de análise que permitem perscrutar o referido sentido, a saber: i) o edifício; ii) a experiência dos utilizadores; iii) o que é escrito a respeito dos edifícios. ${ }^{16}$

Mantendo tudo o que foi dito em mente, e procurando focalizar o objeto de pesquisa, o meu propósito é analisar a evolução do ensino mútuo em Portugal, entre 1835 e 1844, mapeando as mudanças (e também as continuidades) no pensamento acerca do desenho arquitetónico das escolas, dos utensílios e mobiliário escolares, ${ }^{17}$ nomeadamente em função das imposições pedagógico-didáticas. $\mathrm{O}$ arco cronológico apontado merece a seguinte explicitação. No ano de 1835 o ensino mútuo é adotado em Portugal como modo / sistema ${ }^{18}$ oficial e em 1844 inicia-se uma importante reforma do ensino elementar, na qual está já implícita a opção pelo ensino simultâneo. É também importante mencionar que em cada um dos referidos anos é elaborado um diretório do método de ensino mútuo (apenas o primeiro, isto é, o de 1835, é dado à estampa).

\footnotetext{
${ }^{13}$ Recupero esta ideia da obra de Justino Magalhães, Da Cadeira ao Banco. Escola e Modernização (Séculos XVIII-XX) (Lisboa: Educa/Unidade de I \& D de Ciências da Educação, 2010). O meu foco será, pois, no ensino enquanto interação decorrente de operações didáticas e não, propriamente, a nível organizacional.

14 Thomas Markus, Buildings \& Power. Freedom and Control in the Origin of Modern Building Types (New York: Routledge, 1993), 6.

15 Burke \& Grosvenor, School.

16 Markus, Buildings \& Power.

17 Estou, no fundo, a reportar-me às caraterísticas que compreendem a materialidade da escola, isto é, aos seus objetos e tecnologias. Lawn e Grosvenor, Materialities of schooling.

18 Como é sabido, os modos / sistemas de ensino são quatro: individual, simultâneo, mútuo e misto.
} 
Ora, é com base nesses materiais empíricos (textos e elementos gráficos associados) - portanto, naquilo que é escrito e desenhado a respeito dos edifícios-que procurarei alicerçar a minha narrativa. Antes, porém, de prosseguir a finalidade avançada, parece-me útil perspetivar, à luz da investigação já produzida, de que forma se deu em Portugal a apropriação do modelo de ensino mútuo.

\section{A RECEÇÃO PORTUGUESA DO MODELO DE ENSINO MÚTUO: TENSÕES ENTRE O GLOBAL E O LOCAL}

Desenvolvido de forma mais ou menos autónoma pelos educadores ingleses Joseph Lancaster e Andrew Bell, na transição do século XVIII para o século XIX, o ensino mútuo rapidamente excedeu os limites do continente Europeu, chegando às Américas e, mesmo, a África. Há um conjunto de fatores que explica a referida difusão transcontinental, a saber: i) a existência de uma rede de atores (a viagem com uma finalidade educativa teve aqui particular importância); ii) a proliferação de sociedades civis, ligadas, no caso da versão lancasteriana, à British and Foreign School Society (BFSS); iii) a intensa dinâmica de tradução e circulação de materiais impressos (os manuais representam um importante elemento de codificação das práticas de ensino mútuo). ${ }^{19}$

Aquilo que a investigação recente na área das Ciências Socias tem vindo a consagrar, depois dos seminais trabalhos de Jürgen Schriewer (críticos da abordagem neo-institucionalista), é a ideia de que não é legítimo falar em replicação de modelos culturais estandardizados. Em vez disso, na verdade, devemos falar em interpretação ativa desses mesmos modelos em função dos contextos socioculturais e dos atores. ${ }^{20}$ Por exemplo, sabemos hoje que a receção do ensino mútuo variou substan-

\footnotetext{
${ }^{19}$ Carlos Manique da Silva, "Circulating the Monitorial System of Education. The Portuguese Teacher Alexandre Luís da Cunha in the Atlantic World», in Zirkulation und Transformation. Pädagogische Grenzüberschreitungen in Historischer Perspektive, ed. Marcelo Caruso, Thomas Koinzer, Christine Mayer e Karin Priem (Colónia: Böhlau, 2014), 177-190.

${ }^{20}$ Cf., por exemplo, Jorge Ramos do Ó \& Luís Miguel Carvalho, Emergência e circulação do conhecimento psicopedagógico moderno (1880-1960). Estudos comparados Portugal-Brasil (Lisboa: Educa e Unidade de I \& D de Ciências da Educação, 2009); Peter Howlett \& Mary S. Morgan (eds.), How well do facts travel? The dissemination of reliable knowledge (New York: Cambridge University Press, 2011); Martijn van der Burg, «Cultural and legal transfer in Napoleonic Europe: codification of Dutch civil law as a cross-national process», Comparative Legal History, 33 (1), (2015), 85-109.
} 
cialmente de país para país. ${ }^{21}$ Mas também é certo que a interpretação do modelo em alguns contextos já estudados revela inegáveis semelhanças com a sua história em Inglaterra. Essa similitude é, sobretudo, sentida na «base» organizacional do modelo, penso designadamente: i) na delegação da ação pedagógica na figura do monitor; ii) no agrupamento dos alunos por matérias (no essencial, leitura, escrita e aritmética); iii) na regularidade da examinação; iv) na possibilidade de uma progressão desigual nas citadas matérias. ${ }^{22}$ Por outro lado, a produção de significados relacionados com o contexto de acolhimento é visível, por exemplo: i) na noção de ordem —os fenómenos de apropriação em determinadas comunidades deixam entender que não é linear a correspondência entre ordem na sala de aula e ordem social; ${ }^{23}$ ii) na interpretação do papel atribuído ao monitor - percebido, por sua vez, como simples repetidor e não, propriamente, como docente; ${ }^{24}$ iii) na clivagem existente entre a tradição de aprendizagem da escrita em alguns vernáculos e as propostas de Joseph Lancaster. ${ }^{25}$

Do mesmo modo, os estudos sobre a receção portuguesa do ensino mútuo evidenciam a tensão entre as influências estandardizadas -referenciais para todos os países- e os processos seletivos de incorporação, marcados pelos contextos de acolhimento. Desde logo, um dos aspetos que merece ser sublinhado é o da origem militar do «lancasterianismo" português. Na verdade, o primeiro relato acerca da aplicação do modelo em Portugal respeita às escolas de ensino mútuo criadas no

\footnotetext{
${ }^{21}$ Marcelo Caruso (ed.), Classroom Struggle. Organizing Elementary School Teaching in the $19^{\text {th }}$ Century (Frankfurt: Peter Lang, 2015).

${ }^{22}$ Carlos Manique da Silva, «O papel dos materiais impressos na difusão do ensino mútuo: duas traduções portuguesas da obra "Sistema Britânico de Educação", de Joseph Lancaster», in Influencias inglesas en la Educación Española e Iberoamericana (1810-2010), coord. José María Hernández Díaz (Salamanca: Universidade de Salamanca, 2011), 629-639.

${ }^{23}$ Eugenia Roldán Vera, «Order in the Classroom: the Spanish American Appropriation of the Monitorial System of Education», Paedagogica Historica, 41 (6), (2005), 655-675.

${ }^{24}$ Marcelo Caruso, «Locating Educational Authority: teachers monitors, educational meanings and the importing of pedagogical models. Spain and German States in the Nineteenth Century», in Educational Police Borrowing: historical perspectives, eds. David Phillips \& Kimberly Ochs (Oxford: Symposium Books, 2004), 59-87.

${ }^{25}$ Marcelo Caruso, «New Schooling and the Invention of a Political Culture: Community, Rituals and Meritocracy in Colombian Monitorial Schools, 1821-1842», in Imported Modernity in Post-Colonial State Formation. The Appropriation of Political, Educational, and Cultural Models in the Nineteenth-Century Latin America, eds. Marcelo Caruso \& Eugenia Roldán Vera (Frankfurt: Peter Lang, 2007), 277-306.
} 
Exército, corria o ano de 1815. Como bem elucidou Rogério Fernandes, essa circunstância ficou a dever-se ao facto de o Exército português, na sequência das insuficiências reveladas no decurso das três invasões napoleónicas (1807-1810), contar nos seus corpos com oficiais ingleses (alguns deles conhecedores do ensino mútuo). ${ }^{26}$ É interessante, aliás, que a referida circunstância paute depois uma apropriação singular do modelo. Vejamos: Em 1821, é publicada, na cidade do Funchal (Ilha da Madeira), um opúsculo intitulado Breve Esboço do Systema Britanico de Educação, simultaneamente inspirado em duas edições $\left(1 .^{\mathrm{a}} \mathrm{e} 3{ }^{\mathrm{a}}\right.$ ) de uma obra assinada por Joseph Lancaster, a saber: The British System of Education: Being a Complete Epitome of the Improvements and Inventions Practised at the Royal Free Schools... (Londres, 1810); Manual of the System of the British and Foreign School Society of London, for Teaching Reading, Writing, Arithmetic, and Needle-Work... (Londres, 1816). ${ }^{27}$ A intenção era então a de dar consistência à aplicação das técnicas do modelo. Ora, se transcendermos o simples cotejo da face informativa dos textos (originais e tradução), percebemos os aspetos de significação que decorrem da interpretação do tradutor. Na verdade, no plano da reescrita, identificamos a utilização de certas palavras em função do contexto de acolhimento (e, portanto, de novas audiências). Note-se, a propósito, o recurso a termos de inspiração militar, designadamente: "rancho», ${ }^{28}$ para indicar uma subdivisão das classes de leitura e de aritmética correspondente a dez alunos; "oficiais», para designar o mestre e o conjunto dos decuriões ou monitores.

Por outro lado, a introdução de livros didáticos nas escolas de ensino mútuo portuguesas, preconizada, por exemplo, pelo autor do citado Breve Esboço, afastava-se dos fundamentos estabelecidos por Bell e Lancaster. Com efeito, essa via afirmava a ampliação do currículo nas escolas elementares, contrariando, assim, uma ideia cara aos promotores ingleses do modelo: a redução do ensino mútuo às aprendizagens essenciais

\footnotetext{
${ }^{26}$ Rogério Fernandes, «A difusão do ensino mútuo em Portugal no começo do século XIX», in A escola elementar no século XIX. O método monitorial / mútuo, orgzs. Maria Helena Câmara Bastos \& Luciano Mendes de Faria Filho (Passo Fundo: EDIUPF, 1999), 25-43.

27 Carlos Manique da Silva, «Circulating the Monitorial System of Education». Como o próprio nome deixa antever, o Breve Esboço é uma obra síntese (15 páginas), cujo autor / tradutor terá sido Alexandre Luís da Cunha, homem de profundas convicções liberais.

${ }^{28}$ Sobre a conotação militar deste termo, ver Novo Diccionario da Lingua Portugueza (Lisboa: Typografia Rollandiana, 1806).
} 
(ler, escrever e contar), posto que o intento era o de reproduzir (e não o de transformar) a ordem social. E distanciava-se, ainda, da proposta de uma educação assente na leitura de textos da Sagrada Escritura, conforme definiu Lancaster. Aliás, no Breve Esboço é a escrita que recebe a primazia; algo que se prende com a tradição da escola elementar portuguesa, baseada na escrita e na caligrafia.

Há outras clivagens que emergem quando confrontamos a visão do autor do Breve Esboço com a perspetiva veiculada em 1856 por Elizabeth Phelps, responsável pela Sociedade Protetora da Escola de Meninas do Funchal. ${ }^{29}$ Nesse cotejo, a ideia que sobressai é a de que o conhecimento educacional é socialmente construído no seio de redes de comunicação, onde os diferentes atores convergem e divergem uns dos outros. Trata-se, na verdade, de um processo comunicativo que supera a simples lógica do binómio global/local, se quisermos, a tese de que as ideias educativas são produzidas num determinado espaço geográfico e, posteriormente, recebidas num outro contexto (a questão é mais complexa). ${ }^{30}$ Ao mesmo tempo, aquilo que se percebe é que o conhecimento educacional pode ser bastante resiliente.

O sistema em uso (o lancasteriano) é o mais barato que se conhece. A sua economia consiste na ausência de livros ou cartilhas para o ensino elementar, substituindo no seu lugar, lições em pautas de tábua. Estas estão tão duráveis, que a maior parte das que servem hoje na escola estão em uso desde 1821, e este é um dos motivos (ente outros) que obriga a direção a manter a integridade daquele sistema. ${ }^{31}$

Existe outra tradução portuguesa da seminal obra de Joseph Lancaster. Foi publicada em 1823, na cidade do Porto, e saiu da pena de Guilherme Skinner, estudante da Real Academia do Porto, que fixou pra-

\footnotetext{
${ }^{29}$ A Escola em questão era quase exclusivamente suportada por cidadãos britânicos radicados na Ilha da Madeira, sendo de confissão Protestante.

${ }^{30}$ A este respeito, ver Jason Beech \& Alejandro Artopoulos, «Interpreting the circulation of educational discourse across space: searching for new vocabularies», Globalisation, Societies and Education, 14 (2), (2016), 251 - 271.

${ }^{31}$ Instituto dos Arquivos Nacionais/Torre do Tombo (IAN/TT), Ministério do Reino, maço 3571, carta de Elizabeth Phelps a José Ferreira Passos, 1 de julho de 1856, documento sem paginação.
} 
ticamente todo o texto original. ${ }^{32}$ Neste caso, o facto de o tradutor ter tido a intenção de seguir fielmente o The British System of Education (Londres, 1810) - Skinner faz questão de enfatizar que traduziu o texto de Lancaster a partir «do seu original» [leia-se, 1. ${ }^{a}$ edição]— dificulta a perceção dos fenómenos da receção ativa do conhecimento. Ainda assim, mantendo especial atenção ao processo de transmissão textual, é possível identificar divergências e, mesmo, incompatibilidades entre os dois textos (original e tradução) —o ponto, aliás, que procuro sublinhar nesta secção (no fundo, o da tensão entre o global e o local). Por exemplo, ainda que subliminarmente, perpassa um entendimento diferente no que concerne à aplicação de castigos. Com efeito, a versão de 1810 difundia uma série de castigos considerados bárbaros e humilhantes (abandonados pela British and Foreign School Society a partir de 1816), embora a punição corporal estivesse completamente ausente. E se é verdade que

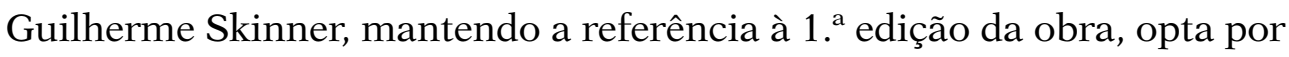
verter para português os ditos castigos (contrários à tradição educativa portuguesa), não deixa, ao mesmo tempo, de omitir certas palavras. Atente-se nas seguintes passagens:

On a repeated or frequent offence, after admonition has failed, the lad to whom an offender presents the card, places a wooden log round his neck, which serves as a pillory, and with this he sent to his seat. This log may weigh from four to six pounds [...] The neck is not pinched our closed confined - it is chiefly burthensome by the manner in which it encumbers the neck, when the delinquent turns to the right or left. ${ }^{33}$

Quando uma ofensa se perpetre muitas vezes, depois da admoestação, o decurião a quem o ofensor apresentar o bilhete lhe porá um pedaço de pau à roda do pescoço, que lhe servirá como uma gonilha, e com isto se manda para o seu lugar. Este pau pesará desde 4 até 6 arráteis [...] $\mathrm{O}$ pescoço não se oprime, mas deve

\footnotetext{
32 Manique da Silva, «O papel dos materiais impressos na internacionalização do ensino mútuo: duas traduções portuguesas da obra "Sistema Britânico de Educação", de Joseph Lancaster».

${ }^{33}$ The British System of Education (London: Joseph Lancaster and Longman $\mathrm{C}^{\circ}$. Paternoster-Row, 1810), 34 .
} 
pôr-se de sorte que, voltando ele a cabeça para a direita ou esquerda, isto lhe embarace o pescoço. ${ }^{34}$

Note-se que não é por acaso que palavra «delinquent» não foi traduzida. $\mathrm{O}$ intento foi expurgar o texto de termos que veiculassem uma imagem da criança enquanto ameaça potencial. De facto, a palavra em questão não era de todo consonante com o ideário liberal da época. Porém, tinha que ver com os fundamentos iniciais do modelo - o que estava em causa para os seus promotores (tanto para Lancaster como para Bell) era o controlo social das classes pobres saídas da Revolução Industrial, consideradas uma ameaça. Na mesma ordem de ideias, Guilherme Skinner afasta-se das similitudes estabelecidas entre processos organizativos do ensino mútuo e manufaturas e, mesmo, de palavras e metáforas relacionadas com o "mundo industrial»; uma posição que expressava a rejeição à ética utilitarista e ao caráter excessivamente mecânico do modelo. Considerem-se os próximos trechos:

The repetition of one word by the monitor, serves to rivet ${ }^{35}$ it firmly on the minds of each one of the class, and also on his own memory. ${ }^{36}$

A repetição de uma palavra pelo decurião serve não somente para a fixar na memória de cada um, mas também na sua. ${ }^{37}$

Termino esta secção ilustrando uma variação importante na apropriação do ensino mútuo em Portugal. Reporto-me a um contexto muito específico -à Casa Pia de Lisboa. Trata-se de uma instituição, fundada em 1780 por Diogo Inácio de Pina Manique, vocacionada para o acolhimento aos órfãos, privilegiando na sua obra educativa o regime de internato. $\mathrm{O}$ ensaio do ensino mútuo que aí tem lugar prolonga-se ininterruptamente por mais de duas décadas (1834-1859). ${ }^{38}$

\footnotetext{
34 Systema Britânico de Educação (Porto: Typ. da Viúva de Alvarez Ribeiro e Filhos, 1823), 59.

35 «Rivet», importa dizê-lo, significa rebitar, cravar.

36 The British System of Education, 11.

37 Systema Britânico de Educação, 27.

38 Carlos Manique da Silva, Do modo de aprender e de ensinar. Renovação pedagógica e cenários de experimentação da escola graduada (1834-1892) (Lisboa: Faculdade de Psicologia e de Ciências da Educação da Universidade de Lisboa, 2008) [tese de doutoramento].
} 
A grande diferença que se observa na perceção do modelo — são evidentes, no entanto, algumas convergências com as práticas e os princípios organizativos definidos por Bell e Lancaster (designadamente, a delegação da ação pedagógica no monitor, a regularidade do exame e a progressão desigual segundo as matérias) — prende-se com a figura do internato e a necessidade dela decorrente de enquadrar disciplinarmente os alunos. Neste último aspeto é nítido, aliás, um afastamento em relação ao Directório das Escolas Primárias -importante texto pedagógico publicado em Portugal no ano de 1835 e destinado a regular o funcionamento das escolas de ensino mútuo-, no qual, em linha com a ideia definida pelos promotores iniciais do modelo, o uso da palmatória e de qualquer outro castigo corporal é expressamente proibido. A questão, porém, é que no contexto institucional da Casa Pia de Lisboa não há qualquer ambiguidade quanto ao valor do castigo corporal. De facto, todo o dispositivo disciplinar se ergue em torno do par recompensa material / punição corporal. ${ }^{39}$ Deixo o leitor com um relato que ilustra bem até que ponto, na década de 1840, eram praticadas as modalidades repressivas.

Foi decidido que o aluno Francisco do Carmo seja castigado com doze açoites sobre a pele, isto em quadrado, aonde deverão formar todos os alunos, e no dia seguinte lhe serão dadas seis palmatoadas na aula perante todos os mais alunos: estes castigos são-lhe aplicados em consequência do ato de insubordinação por ele praticado na aula de ensino mútuo. ${ }^{40}$

\section{MUDANÇAS (E CONTINUIDADES) NA MATERIALIDADE DAS ESCOLAS DE ENSINO MÚTUO À LUZ DOS DIRETÓRIOS DO MÉTODO}

Uma das atrações do ensino mútuo residiu no facto de oferecer uma pedagogia sistemática, plasmada em diversos materiais impressos (panfletos, manuais, livros,...), traduzidos ou adaptados a partir das obras de Joseph Lancaster e veiculados pela BFSS. De resto, na secção anterior quis deixar patente a importância dos referidos materiais na circulação do conhecimento pedagógico e na codificação das práticas. Ora, no caso

${ }^{39}$ Carlos Manique da Silva, Do modo de aprender e de ensinar.

${ }^{40}$ Arquivo Histórico da Casa Pia de Lisboa, Atas da Administração da Casa Pia, 1842-1847, sessão de 18 de janeiro de 1843, fl. 17. 
português, esse pressuposto é particularmente entendido pelo Estado no momento em que o ensino mútuo é adotado como modo / sistema oficial (Decreto de 7 de setembro de 1835, Reforma de Rodrigo da Fonseca Magalhães). É então clara, pela primeira vez, a ideia de generalizar um sistema uniforme de educação para todo o país. E é exatamente com esse propósito que é publicado, na Imprensa Nacional, o já referido Directório das Escolas Primárias. Trata-se, no fundo, de um manual ou guia, no sentido em que codifica um conjunto de práticas destinado a orientar os professores. É difícil perceber a filiação do Directório, uma vez que, depois da década de 1820, os livros da autoria de Joseph Lancaster deixam de ser traduzidos. No entanto, na mencionada década e na seguinte são publicados, em todos os continentes e em diversos vernáculos, «manuais« ou «guias» do método. ${ }^{41}$ Com segurança, aquilo que se pode afirmar é que o Directório é o resultado de várias influências. Além de texto escrito (17 capítulos, 77 pp.), inclui no final uma estampa (planta / alçado de sala de aula) e algumas tabelas de registo (matrícula e frequência de alunos,...). Por outro lado, nos capítulos são abordados os seguintes tópicos / temas: local e mobília da escola; processos de ensino das várias disciplinas (escrita, leitura, aritmética, gramática, desenho linear e catecismo moral civil); distribuição das horas e dos trabalhos; férias; ordens de execução; monitores; prémios e castigos; exames; registos; ordem e disciplina da escola em geral; organização da escola; oração.

Também não se afigura fácil perceber em que medida o dito documento - em vigor até 1850, ano em que é regulamentada a Reforma Geral da Instrução Pública de Costa Cabral (1844)— foi seguido nas escolas portuguesas. ${ }^{42}$ Há relatos, por exemplo, que indiciam um claro afastamento em relação ao que se achava prescrito no Directório (nomeadamente, volto a referir, no correlato à disciplina). ${ }^{43}$

Mas, para a minha agenda de investigação, aquilo que interessa enfatizar é que entre 1835 e os primeiros anos da década de 1840 se assiste

\footnotetext{
${ }^{41}$ Marcelo Caruso (coord.), Globalization and Printing. An International Research Guide for the History of the Bell-Lancaster System of Mutual Teaching in the $19^{\text {th }}$ Century (Berlim: manuscrito, 2007).

42 Em Portugal, na década de 1830, o ensino mútuo foi essencialmente ensaiado em contexto de ensino normal. Em 1839-40, por exemplo, existiam no país escolas normais pelo método de ensino mútuo em 13 capitais de distrito, sendo que o número total de alunos rondava os 1600. Manique da Silva, Do modo de aprender e de ensinar.

43 Manique da Silva, Do modo de aprender e de ensinar.
} 
à introdução de pequenas mas significativas mudanças no campo educativo. É exatamente nesse processo de mudança que pretendo começar a focar-me. Vejamos: Em 1841, por portaria de 2 de julho, é criada uma comissão para rever o Directório. ${ }^{44}$ Só passados quatro anos, isto é, no início de julho de 1845, em boa medida devido à permanente situação de conflitualidade política vivida no país, o Conselho Superior de Instrução Pública (CSIP) se pronuncia sobre o assunto, nos termos que se seguem:

[O CSIP] não tem por conveniente a reforma do Diretório, acima indicado, porquanto se reduz, em relação ao que existia em alterações de pouca monta, e algumas deficiências na prática, como o Conselho viu pela execução delas em uma das escolas do ensino mútuo.

Que acha suficiente o antigo Diretório [...] e que seja indispensável novo diretório quando venha a seguir-se o ensino simultâneo. ${ }^{45}$

A posição do CSIP, denunciando a preferência pelo ensino simultâneo, ${ }^{46}$ viria a revelar-se determinante. De facto, o documento produzido pela comissão nomeada em 1841 -refiro-me a um novo Directório das Escolas Primárias, datado de 1844- nunca foi publicado. ${ }^{47}$ Trata-se, porém, de uma obra extremamente interessante quando cotejada com a versão de 1835. Com efeito, e não obstante a organização dos capítulos ser aproximadamente a mesma ${ }^{48}$ (algo que evidencia o sentido de conti-

\footnotetext{
${ }^{44}$ IAN/TT, Ministério do Reino, maço 3535.
}

45 Idem, documento sem paginação.

46 Do ponto de vista sociológico, uma autora como Anne Querrien explica as razões que conduziram ao desaparecimento do ensino mútuo, em meados do século XIX. Uma das questões fundamentais prende-se com a dissociação da autoridade pedagógica (e, obviamente, dos planos disciplinar e moral) da presença exclusiva de adultos. Por outras palavras, a socialização do aluno como ser moral encontra-se desvinculada da autoridade pessoal do professor. E não era esse o princípio dominante na sociedade. A autora sublinha, assim, a dificuldade do ensino mútuo se inscrever no corpo social, algo que está ligado, no caso francês, à preexistência predominante das escolas lassalianas (as quais servem de referência). Anne Querrien, L'école mutuelle: une pédagogie trop efficace? (Paris: les Empêcheurs de penser en rond, 2005).

47 Consultei um exemplar manuscrito no IAN/TT, Ministério do Reino, maço 3535.

48 Relativamente ao anterior Diretório, o documento de 1844 (112 páginas de texto escrito, mais três imagens e seis tabelas de registo) apresenta como grande diferença a introdução de um capítulo intitulado «Da instrução dos monitores ou da classe de ampliação e aperfeiçoamento do ensino primário». Assunto ao qual regressarei. 
nuidade nas práticas), o Directório de 1844 plasma pequenas mudanças decorrentes da evolução das práticas pedagógico-didáticas adotadas nas escolas normais de ensino mútuo desde $1835 .{ }^{49}$ Ora, esse processo de mudança é particularmente sentido quando se analisa a materialidade das escolas à luz dos dois Diretórios. O que mudou então entre 1835 e 1844? Antes de responder a essa questão, julgo importante reforçar tanto o princípio básico do modelo - o «ensino pelos pares»-quanto as caraterísticas que constituem a materialidade das escolas, isto é, os objetos e as tecnologias. ${ }^{50}$ Para o efeito, recorro a uma descrição da autoria de Roldán Vera:

The school (a single, large classroom) was divided into small groups or classes of children according to the progress they achieved in each subject: reading, writing, arithmetic and religion [...]. Each class was conducted by a monitor or instructor, who was a student with greater expertise in that particular subject $[\ldots]$. These monitors were instructed by the teacher in advance about what and how they had to teach their groups. Lessons were short, lasting from fifteen to thirty, and students moved constantly from one place in the classroom to another: writing was taught while the students were sitting in rows, with the use of sand boxes and sticks, whereas reading and arithmetic were learned by standing in semicircles around teaching posts on which cards with the lesson were hung [...]. There were rules meticulously designed for every act that took place in the classroom. Everything was done at a command uttered by the monitors, in an almost military manner. Orders like «in!» (to enter the classroom), «hands out!», « clean slates!», «show slates!», «slates down!», «write!», etc., regulated the course of the learning experience. ${ }^{51}$

\footnotetext{
${ }^{49}$ É importante dizer que a comissão que elaborou o Directório de 1844 era composta pelo comissário dos estudos, Francisco Freire de Carvalho, na qualidade de presidente, e pelos vogais, professores do ensino público, Francisco António de Michellis, António Soares Teixeira, Joaquim António de Bastos e João António Lacerda.

${ }^{50}$ Lawn \& Grosvenor, Materialities of schooling

${ }^{51}$ Eugenia Roldán Vera, «The Monitorial System of Education and Civic Culture in Early Independent Mexico», Paedagogica Historica, 35 (2), (1999): 305.
} 
Atendendo à elevada especialização do espaço escolar e ao especial cuidado com o equipamento e mobiliário escolares, não surpreende que os manuais de Joseph Lancaster dediquem um capítulo (significativamente, o primeiro) ao "local e mobília da escola». ${ }^{52} \mathrm{E}$ se é verdade que no processo de difusão mundial do modelo de ensino mútuo os ditos manuais (que incluíam texto e estampas) foram, em larga medida, prescritivos — sublinho, para a minha agenda de investigação, os aspetos correlatos à organização do espaço escolar-, ainda assim não se pode falar em "cópia» mas em reinterpretação. Esta questão fica patente num trecho de uma carta enviada pelo cidadão britânico Joseph Phelps (promotor do ensino mútuo na ilha da Madeira) à BFSS, a propósito da construção de um edifício escolar. Com efeito, se a referência é a Escola de Borough Road, fundada em Londres por Joseph Lancaster, percebe-se, ao mesmo tempo, que estamos perante processos seletivos de transformação (no caso presente, no respeitante às técnicas de construção adotadas e aos materiais usados).

Our school-room is not yet finished [...]. I should take upon myself to order the iron legs for a School upon the plan laid down in the Manual for 304 boys [...]. The four walls are built and paid for. The wood-work of the roof will be ready in a few days (paid for). The tiles are likewise purchased and paid for. Lime is the only material I have not provided, but can purchase it cheap. It is very nearly determined to floor the room with boards, it being thought the cheapest. We must have patience with the noise, and try to stop it as much as possible by hanging festoons of cloth across the room, as at the Borough Road. ${ }^{53}$

Enfatizada, uma vez mais, a posição de princípio de que devemos falar em interpretação ativa de modelos (difundidos a nível mundial) em função dos contextos socioculturais e dos atores (e não em simples replicação dos mesmos), passo, agora, a olhar para as caraterísticas que constituem a materialidade da escola, tendo exatamente como fonte os dois Diretórios (1835 e 1844). A Tabela 1 sistematiza o levantamento efetuado.

${ }^{52} \mathrm{O}$ mesmo sucede nos dois Diretórios que utilizo como fonte no presente estudo.

${ }^{53}$ BFSS Annual Report, 1824: 128. 
Tabela 1. Materialidade das Escolas de Ensino Mútuo, 1835-184454

\begin{tabular}{|c|c|c|c|}
\hline & $\begin{array}{l}\text { Directório das Escolas } \\
\quad \text { Primárias (1835) }\end{array}$ & \multicolumn{2}{|c|}{ Directório das Escolas Primárias (1844) } \\
\hline Número de salas & - Uma sala & \multicolumn{2}{|c|}{$\begin{array}{l}\text { - Uma sala (aula comum) } \\
\text { - Uma sala para a classe de aperfeiçoamento } \\
\text { (monitores) }\end{array}$} \\
\hline Número de alunos & $\begin{array}{l}\text { - } 100 \text { alunos (para uma } \\
\text { sala com } 36 \text { pés de } \\
\text { comprimento e } 20 \text { pés } \\
\text { de largura) }\end{array}$ & \multicolumn{2}{|c|}{$\begin{array}{l}\text { - } 100 \text { alunos (para uma sala com } 68 \text { palmos de } \\
\text { comprimento e } 36 \text { palmos de largura) }\end{array}$} \\
\hline $\begin{array}{l}\text { Professores } \\
\text { Monitores }\end{array}$ & $\begin{array}{l}\text { - } 1 \text { mestre } \\
\text { - } 6 \text { monitores gerais. } 20 \\
\text { monitores de classe } \\
\text { com adjuntos } \\
\text { - ? monitores de grupos } \\
\text { (em função do número } \\
\text { de alunos de cada } \\
\text { classe) }\end{array}$ & \multicolumn{2}{|c|}{$\begin{array}{l}\text { - } 1 \text { professor } \\
\text { - } 4 \text { monitores gerais } \\
\text { - } 20 \text { monitores de classe (com adjuntos?) } \\
\text { - ? monitores de grupos (em função do número de } \\
\text { alunos de cada classe) } \\
\text { - } 1 \text { Porteiro }\end{array}$} \\
\hline & \multirow[b]{2}{*}{$\begin{array}{l}\text { - Estrado, cadeira, mesa } \\
\text { e escrivaninha do } \\
\text { mestre } \\
\text { - Cadeiras para os } \\
\text { visitadores. Mesas em } \\
\text { forma de escrivaninha } \\
\text { (para os alunos) } \\
\text { - Bancos } \\
\text { - Tabelários ou porta- } \\
\text { tabelas (fixados a cada } \\
\text { mesa) } \\
\text { - Gavetas (para guardar } \\
\text { os lápis) } \\
\text { - Semicírculos para } \\
\text { leitura junto às paredes } \\
\text { - Estantes, junto aos } \\
\text { quadros negros, para } \\
\text { guardar instrumentos } \\
\text { de desenho linear } \\
\text { - Relógio }\end{array}$} & Aula comum & $\begin{array}{c}\text { Sala classe } \\
\text { Aperfeiçoamento }\end{array}$ \\
\hline $\begin{array}{l}\text { Layout da sala } \\
\text { e mobiliário }\end{array}$ & & $\begin{array}{l}\text { - Estrado, cadeira, mesa } \\
\text { e escrivaninha do } \\
\text { professor } \\
\text { - Cadeiras para os } \\
\text { visitadores } \\
\text { - Carteiras. Bancos. } \\
\text { Porta-tabelas (fixados a } \\
\text { cada mesa) } \\
\text { - Semicírculos para } \\
\text { leitura junto às paredes } \\
\text { - Estante (sobre o } \\
\text { estrado, para guardar } \\
\text { livros e mais objetos) } \\
\text { - Relógio }\end{array}$ & $\begin{array}{l}\text { - Mesa grande (para nela } \\
\text { poder haver exercícios } \\
\text { de escrita) } \\
\text { - Escrivaninha para o } \\
\text { professor } \\
\text { - Cadeiras (para o } \\
\text { professor e visitadores) } \\
\text { - Bancos grandes em } \\
\text { volta da casa para os } \\
\text { alunos se sentarem } \\
\text { - Estante (para guardar } \\
\text { livros e vários } \\
\text { utensílios) }\end{array}$ \\
\hline Utensílios de escrita & $\begin{array}{l}\text { - Mesa com areia, } \\
\text { tinteiros, ardósias, lápis } \\
\text { e canetas, penas, papel, } \\
\text { giz }\end{array}$ & $\begin{array}{l}\text { - Mesa com areia, } \\
\text { tinteiros, ardósias, } \\
\text { lápis, penas, papel, giz }\end{array}$ & $\begin{array}{l}\text { - Tinteiros, penas, giz, } \\
\text { papel }\end{array}$ \\
\hline
\end{tabular}

${ }^{54}$ Tabela baseada na investigação de Eugenia Roldán Vera, «From Monitorial to Graded Schooling in $19^{\text {th }}$ Century Mexico: Politics and Pedagogy in the Definition of Modern Education", in Classroom Struggle. Organizing Elementary School Teaching in the $19^{\text {th }}$ Century, ed. Marcelo Caruso (Frankfurt: Peter Lang, 2015), 183-184. 


\begin{tabular}{|c|c|c|c|}
\hline & $\begin{array}{c}\text { Directório das Escolas } \\
\text { Primárias (1835) }\end{array}$ & \multicolumn{2}{|c|}{ Directório das Escolas Primárias (1844) } \\
\hline $\begin{array}{c}\text { Quadros pretos e } \\
\text { tabelas }\end{array}$ & $\begin{array}{l}\text { - Quadros negros para } \\
\text { desenho linear e } \\
\text { aritmética (junto aos } \\
\text { semicírculos) } \\
\text { - Tabelas (de leitura) nas } \\
\text { paredes } \\
\text { - Tabela de honra e } \\
\text { quadro negro (na } \\
\text { parede acima do } \\
\text { estrado) }\end{array}$ & $\begin{array}{l}\text { - Tábua preta com o seu } \\
\text { cavalete (sobre o } \\
\text { estrado) } \\
\text { - Tábuas pretas para } \\
\text { desenho linear } \\
\text { - Tabelas de leitura, } \\
\text { geografia, aritmética } \\
\text { - Quadro de honra e } \\
\text { quadro negro } \\
\text { (suspensos ao lado do } \\
\text { estrado) }\end{array}$ & $\begin{array}{l}\text { - Duas tábuas pretas } \\
\text { maiores que as da } \\
\text { "primeira aula» (para } \\
\text { os exercícios de } \\
\text { aritmética, desenho } \\
\text { linear, etc.) }\end{array}$ \\
\hline $\begin{array}{c}\text { Outros objetos de } \\
\text { ensino }\end{array}$ & $\begin{array}{l}\text { - Ponteiros dos } \\
\text { monitores, campainha, } \\
\text { telégrafos, exemplares } \\
\text { graduados de escrita, } \\
\text { cadernos para as } \\
\text { matérias, apito, } \\
\text { «modelos de escrita», } \\
\text { réguas graduadas, } \\
\text { livros }\end{array}$ & $\begin{array}{l}\text { - Ponteiros dos } \\
\text { monitores, campainha, } \\
\text { apito, telégrafos, } \\
\text { exemplares graduados } \\
\text { de escrita, cadernos } \\
\text { para escrita, pequenos } \\
\text { compêndios, réguas } \\
\text { graduadas, compassos, } \\
\text { esquadros graduados, } \\
\text { livros }\end{array}$ & $\begin{array}{l}\text { - } 1 \text { Compasso } \\
\text { - } 1 \text { régua graduada } \\
\text { - } 1 \text { semicírculo graduado } \\
\text { - } 1 \text { esquadro } \\
\text { - } 1 \text { ponteiro } \\
\text { - Cartas geográficas } \\
\text { - } 1 \text { globo terrestre ou } \\
\text { esfera } \\
\text { - Coleção de livros para } \\
\text { as diferentes disciplinas }\end{array}$ \\
\hline Disciplinas & $\begin{array}{l}\text { - Escrita; leitura; } \\
\text { aritmética; gramática; } \\
\text { desenho linear; } \\
\text { catecismo moral, civil, } \\
\text { religioso e político; } \\
\text { «compêndio geográfico } \\
\text { e histórico» }\end{array}$ & \multicolumn{2}{|c|}{$\begin{array}{l}\text { - Escrita; leitura; aritmética; gramática; desenho } \\
\text { linear; geografia; história sagrada e catecismo } \\
\text { político e civil; catecismo religioso }\end{array}$} \\
\hline
\end{tabular}

Fonte: Elaboração própria a partir de Directório das Escolas Primárias, Lisboa, Imprensa Nacional, 1835; Directório das Escolas Primárias, Lisboa, 1844 (IAN/TT, Ministério do Reino, maço 3535).

Nota: A indicação das disciplinas que constituíam o currículo serve para contextualizar a utilização de determinados objetos de ensino.

Tendo por referência a Tabela 1, que organiza as mudanças e as continuidades na materialidade das escolas de ensino mútuo à luz dos dois citados Diretórios, julgo importante dizer que, sensivelmente no espaço temporal de uma década, o modelo evolui lenta e gradualmente. Note-se que, para as «aulas comuns», se mantêm praticamente: i) o número de monitores; ii) o layout da sala e mobiliário; os utensílios de escrita; iii) os quadros pretos e tabelas; iv) outros objetos de ensino. No entanto, há pequenas evoluções que se afiguram muito significativas. Por exemplo, é notório que a mudança no sentido da afirmação da «instrução direta» 
a um grupo de alunos sob a liderança de um professor começa com o ensino mútuo, nos anos de 1840. De facto, a existência de uma sala de aula destinada à classe de aperfeiçoamento (unicamente prevista no Diretório de 1844) encerra esse mesmo pressuposto - no fundo, o do ensino simultâneo. Veja-se, de resto, que na década de 1840 há notícia da separação / autonomização de espaços arquitetónicos para a instrução de uma só «classe» sob a direção exclusiva de um professor. ${ }^{55}$ Este raciocínio fica mais claro se se descrever o que se achava prescrito no Diretório de 1844, relativamente à «classe» de aperfeiçoamento (destinada aos monitores):

Dirigirão pois os professores a instrução dos seus discípulos nesta classe, pela forma que julgarem mais conveniente [...]. Servir-seão para isso dos compêndios [...] e que sejam idênticos em cada assunto, não só a fim de que esta instrução siga em tudo uma uniformidade regular; como também para que a lição de cada um seja igual à de todos, e a de todos equivalente à de cada um, único meio de se tirar a maior vantagem possível destas lições.

É pois nesta classe que o professor deve com especialidade empregar todo o seu zelo, para que os seus discípulos, nas lições de escrita, aprendam a desempenhá-las com perfeição, fazendo-lhes para isso de vez em quando uma explicação mais larga de todos os preceitos caligráficos, demonstrados na pedra negra. ${ }^{56}$

Apesar de não ser uma ideia proeminente no Diretório de 1844 (uma vez que concerne apenas à «classe» dos monitores), ganha corpo ser mais eficaz (vantajoso, para seguir à letra o texto) um grupo de alunos receber instrução sobre a mesma matéria por um único professor e num espaço autónomo. Porém, não estamos ainda a falar da convergência que acontecerá nos anos de 1870-1880 entre um professor, uma sala, uma classe. ${ }^{57}$

${ }^{55}$ Por exemplo, em novembro de 1843, num orçamento de obras elaborado para a escola de Ensino Mútuo de Castelo Branco, prevê-se uma "parede e porta para separar a aula comum da casa para lição de desenho linear e gramática». IAN/TT, Ministério do Reino, maço 3531, processo 113, documento sem paginação.

${ }^{56}$ Directório das Escolas Primárias, Lisboa, 1844: 106 (IAN/TT, Ministério do Reino, maço 3535).

${ }^{57}$ Cf., a este respeito, David Hamilton, Towards a Theory of Schooling (London: The Falmer Press, 1989). 
Como quer que seja, sublinhe-se o facto de o ensino mútuo introduzir racionalidade, ordem e uniformidade ${ }^{58}$ conduzindo a uma mudança decisiva e irreversível na paisagem pedagógica que se traduz na passagem da figura do «tutor» à do professor (o primeiro utilizava o método individual; o segundo, o método simultâneo, mútuo e, em alguns casos, uma combinação dos dois). ${ }^{59}$

Importante, do mesmo modo, é considerar a evolução do ensino mútuo à luz das mudanças que vão sendo introduzidas pelos professores em função da sua própria prática letiva (não por acaso, o método surge associado às escolas normais). E aqui é útil recorrer à tese de David Tyack e Larry Cuban, segundo a qual os professores procuram maior eficácia pedagógica através da integração, nos seus reportórios, de práticas letivas consideradas úteis. ${ }^{60} \mathrm{E}$ se é verdade que esse aspeto está patente na última citação - refiro-me, designadamente, à normalização da utilização do quadro preto, de maiores dimensões, aliás, daquele que era aconselhado para a "aula comum», assim como à valorização dos compêndios e de algumas tecnologias de escrita (cf. também a Tabela 1)—, não menos interessante será pôr em evidência de que forma as necessidades didáticas podem fazer evoluir o espaço escolar. Atente-se na seguinte descrição da aula de ensino mútuo proposta no Diretório de 1844:

As curvas para a formatura dos grupos de leitura devem ser abertas no chão, em toda a circunferência da aula, junto à parede; e embutidas de madeira de cor, ou pintadas. Estas curvas, ou grandes arcos de círculo, cujas extremidades tocarão na parede, devem ser iguais a duas terças partes do mesmo círculo, sendo o seu diâmetro de nove palmos, de seis de corda que toca na parede; e ficando o seu centro dela distante de um palmo e meio. Deu-se preferência a esta figura a fim de que os discípulos dos dois lados fiquem mais próximos da tabela; remediando por esta

\footnotetext{
${ }^{58}$ Do ponto de vista organizacional, veja-se o que o modelo de ensino mútuo encerra: distribuição precisa dos corpos na sala de aula; controlo das suas atividades através da definição de rotinas (e de sincronismos); existência de um horário e de um plano de estudos; regras precisas para a classificação dos alunos.

${ }^{59}$ Gianfranco Bandini, «From Tutor to Teacher: The Birth of Popular Schooling in Early $19^{\text {th }}$ Century Italy", in Classroom Struggle. Organizing Elementary School Teaching in the $19^{\text {th }}$ Century, ed. Marcelo Caruso (Frankfurt: Peter Lang, 2015), 205-228.

${ }^{60}$ David Tyack e Larry Cuban, Tinkering toward Utopia: a century of public school reform (Cambridge, MA: Harvard University Press, 1995).
} 
forma o inconveniente que resultava da diferente posição dos discípulos nos semicírculos, até agora usados, a qual não era tão vantajosa. ${ }^{61}$

Figura 1. Planta de uma escola de ensino mútuo para 100 alunos

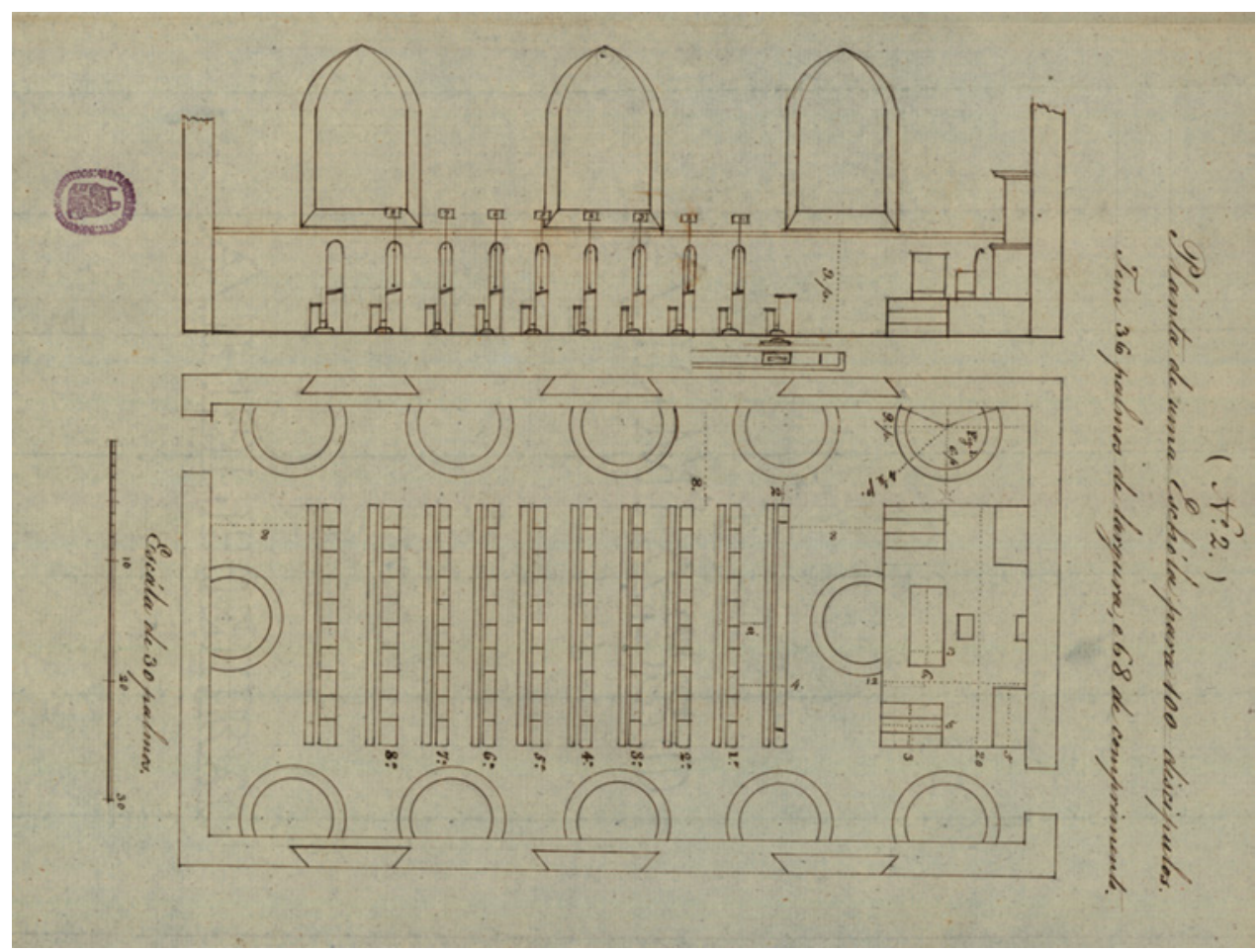

Fonte: Directório das Escolas Primárias, Lisboa, 1844 (IAN/TT, Ministério do Reino, maço 3535). Nota: Imagem cedida pelo IAN/TT.

Ora, aquilo que pretendo argumentar é que, no decurso da década de 1840, algumas das mudanças que ocorrem no desenho arquitetónico das escolas de ensino mútuo, sublinho, nomeadamente, a autonomização de espaços para a instrução de uma só «classe», decorrem de imposições pedagógico-didáticas, isto é, são consequência da interação professor / alunos em situação de ensino e aprendizagem. Todavia, é importante di-

${ }^{61}$ Directório das Escolas Primárias, Lisboa, 1844: 11(IAN/TT, Ministério do Reino, maço 3535). Sublinhado meu. 
zer que a "classe» é relativamente arbitrária, ou seja, no caso específico da «classe» dos monitores, a ideia de homogeneização do grupo (que começa a imperar a partir do início do século XIX) ${ }^{62}$ alicerça-se numa operação didática: todos os alunos seguem a mesma lição do compêndio (recupere-se a descrição do Diretório de 1844). Por outras palavras, a «classe» não é ainda fundada em critérios que se prendem com a similaridade dos elementos que a constituem (por exemplo, idade e proficiência). Porém, numa perspetiva organizacional, convém ter presente que as «monitorias» do ensino mútuo assentavam no seguinte princípio: a proficiência dos alunos numa determinada matéria. Estamos a caminho de uma evolução — baseada na secular matriz da «classe» de J.-B. de La Salle- que fará progressivamente corresponder a cada « classe» um «conjunto de alunos da mesma idade e nível de estudos, um espaço, um professor e um plano de estudos distintos». ${ }^{63}$ As razões que vão determinar tal regularidade organizacional (praticamente imutável até aos dias de hoje) são bem descritas por Larry Cuban:

Teaching the entire class together is an efficient and convenient use of teacher's time - a valuable and scarce resource - to cover the mandated content and to maintain control. Lecturing, recitation, seatwork, homework drawn from texts, and weekly tests are efficient, uncomplicated ways of transmitting knowledge to groups and determining whether students have learned the material. ${ }^{64}$

Por outro lado, é evidente que há um aspeto que será determinante nessa evolução. Refiro-me à presença mais ativa do professor na instrução, a partir da década de $1840 .{ }^{65}$ Em boa medida, tal facto decorre do intento de socialização do aluno como ser moral (em agenda os objetivos que o poder comete à instituição escolar) estar necessariamente vinculado à autoridade pessoal do professor. Note-se, aliás, que uma das prin-

${ }^{62}$ Hamilton, Towards a Theory of Schooling.

${ }^{63}$ João Barroso, «O Século da Escola: do Mito da Reforma à Reforma de um Mito», in O Século da Escola. Entre a Utopia e a Burocracia, ed. Teresa Ambrósio, Eduardo Terren, Daniel Hameline \& João Barroso (Porto: Editora ASA, 2001), 69.

${ }^{64}$ Larry Cuban, How Teachers Taught. Constancy and Change in American Classrooms 1890-1990 (New York e London: Teachers College Press, 1993), 18.

${ }^{65}$ Veja-se a própria alteração de terminologia (de 1835 para 1844): «mestre» dá lugar a «professor» (cf. Tabela 1). 
cipais críticas verberadas ao ensino mútuo, sobretudo a partir de finais da década de 1820, dependendo dos contextos socioculturais, incidia no seu princípio básico: a delegação da ação educativa na figura do monitor.

\section{CONCLUSÕES}

Num primeiro momento do presente ensaio, tomando como fonte uma série de estudos sobre a receção do ensino mútuo no contexto português, sublinhei a pluralização dessa tecnologia educativa no curso da sua difusão mundial. Todavia, a produção de significados relacionados com o contexto de acolhimento não é incompatível com a manutenção da integridade do modelo, particularmente visível na sua «base» organizacional (a delegação da ação pedagógica na figura do monitor, o agrupamento dos alunos por matérias, a regularidade da examinação / classificação,...).

Num segundo momento, analisando a materialidade das escolas de ensino mútuo entre os anos de 1835 e 1844, à luz de dois diretórios do método redigidos em Portugal (abordados, porém, enquanto produtos da difusão e da interpretação do conhecimento pedagógico), defendi que algumas das mudanças que então se observam, nomeadamente, no desenho arquitetónico das escolas, são determinadas pela interação professor / alunos em situação de ensino e aprendizagem. Por outras palavras não deixando de considerar que o ensino mútuo exerce uma influência decisiva na definição de uma organização pedagógica para a escola primária pública, sobretudo por via do apurado processo de classificação dos alunos (em causa, a ideia de nível de instrução apropriado, bem presente nas «monitorias»)—, demonstrei que a transformação da "classe» num módulo organizativo para departamentalizar o espaço escolar, para seguir quase à letra uma expressão de João Barroso, é também tributária de operações didáticas (e não apenas de medidas organizacionais). Nos anos de 1840, a progressiva autonomização de espaços nos quais um professor ensina um grupo de alunos é, a esse respeito, bem elucidativa. De facto, à mencionada autonomização estão associadas novas práticas pedagógicas alicerçadas em procedimentos didáticos (recorde-se a naturalização da utilização do compêndio). Por outro lado, é de igual modo por via da presença mais ativa do professor no processo de instrução, justamente a partir da década de 1840, que é superada a dupla separação 
arquitetónica entre salas destinadas a acolher um elevado número de alunos (ensinados pelos pares) e salas de aulas autónomas (nos quais pequenos grupos de alunos são ensinados por um professor).

\section{Nota sobre o autor:}

Carlos Manique da Silva é investigador da Unidade de Investigação e Desenvolvimento em Educação e Formação (Instituto de Educação da Universidade de Lisboa). Doutorado em Ciências da Educação (especialidade História da Educação), tem como áreas de interesse a circulação e difusão do conhecimento pedagógico, a escola graduada, o ensino mútuo e a arquitetura escolar. De entre as suas publicações, salienta-se: Escolas Belas ou Espaços Sãos? Uma Análise Histórica Sobre a Arquitetura Escolar Portuguesa (1860-1920) (Lisboa: IIE, 2002). Tem colaborado em vários projetos de investigação de que se destacam: Liceus de Portugal e Educação e Património Cultural: Escolas, Objetos e Práticas. Foi professor visitante nas Universidades Estaduais de S. Paulo e de Santa Catarina (Brasil), e na Universidade de Oviedo (Espanha).

\section{Referências:}

BandinI, Gianfranco. «From Tutor to Teacher: The Birth of Popular Schooling in Early $19^{\text {th }}$ Century Italy». In Classroom Struggle. Organizing Elementary School Teaching in the $19^{\text {th }}$ Century, edited by Marcelo Caruso, 205-228. Frankfurt: Peter Lang, 2015.

BARRoso, João. "O Século da Escola: do Mito da Reforma à Reforma de um Mito». In O Século da Escola. Entre a Utopia e a Burocracia, edited by Teresa Ambrósio, Eduardo Terren, Daniel Hameline and João Barroso. Porto: Editora ASA, 2001.

- «Innovation and change in school: challenges to teachers and architects». Education Buildings and Equipment 28 (2002).

$\mathrm{BEECH}$, Jason, and Alejandro Artopoulos. "Interpreting the circulation of educational discourse across space: searching for new vocabularies». Globalisation, Societies and Education 14 (2) (2016): 251-271.

BFSS Annual Report, 1824.

BURG, Martijn van der. «Cultural and legal transfer in Napoleonic Europe: codification of Dutch civil law as a cross-national process». Comparative Legal History 33 (1) (2015): 85-109. 
Burke, Catherine, and Ian Grosvenor. School. London: Reaktion Books, 2008.

CARUSO, Marcelo. «Locating Educational Authority: teachers monitors, educational meanings and the importing of pedagogical models. Spain and German States in the Nineteenth Century». In Educational Police Borrowing: historical perspectives, edited by David Phillips and Kimberly Ochs, 59-87. Oxford: Symposium Books, 2004.

- Classroom Struggle. Organizing Elementary School Teaching in the $19^{\text {th }}$ Century. Frankfurt: Peter Lang, 2015.

- Globalization and Printing. An International Research Guide for the History of the Bell-Lancaster System of Mutual Teaching in the 19 $9^{\text {th }}$ Century. Berlim: manuscrito, 2007.

- «New Schooling and the Invention of a Political Culture: Community, Rituals and Meritocracy in Colombian Monitorial Schools, 1821-1842». In Imported Modernity in Post-Colonial State Formation. The Appropriation of Political, Educational, and Cultural Models in the Nineteenth-Century Latin America, edited by Marcelo Caruso and Eugenia Roldán Vera, 277-306. Frankfurt: Peter Lang, 2007.

CÁssia Gonçalves, Rita de. Arquitetura Flexível e Pedagogia Ativa: um (des)encontro nas escolas de espaços abertos. Lisboa: Instituto de Educação da Universidade de Lisboa, 2011.

Cuban, Larry. How Teachers Taught. Constancy and Change in American Classrooms 1890-1990. New York e London: Teachers College Press, 1993.

DuARTE, Alexandra, Luísa Veloso and Joana Marques. "Changing education through learning spaces: impacts of the Portuguese schools buildings' renovation programme». Cambridge Journal of Education 44 (3) (2014): 401-423.

FERnANDES, Rogério. "A difusão do ensino mútuo em Portugal no começo do século XIX». In A escola elementar no século XIX. O método monitorial / mútuo, organizadores Maria Helena Câmara Bastos and Luciano Mendes de Faria Filho, 25-43. Passo Fundo: EDIUPF, 1999.

Hamilton, David. Towards a Theory of Schooling. London: The Falmer Press, 1989.

Herman, Frederik, Angelo Van Gorp, Frank Simon, Bruno Vanobbergen and Marc Depaepe. «Modern architecture meets new education. Renaat Braem's design and the Brussels Decroly school». Revue Belge d'Histoire Contemporaine XLI (2011).

Howlett, Peter, and Mary S. Morgan, eds. How well do facts travel? The dissemination of reliable knowledge. New York: Cambridge University Press, 2011.

LAWN, Martin, and Ian Grosvenor. Materialities of schooling: Design, technology, objects, routines. Oxford: Symposium Books, 2005. 
Magalhães, Justino. Da Cadeira ao Banco. Escola e Modernização (Séculos XVIII-XX). Lisboa: Educa/Unidade de I \& D de Ciências da Educação, 2010.

Manique da Silva, Carlos. «Circulating the Monitorial System of Education. The Portuguese Teacher Alexandre Luís da Cunha in the Atlantic World». In Zirkulation und Transformation. Pädagogische Grenzüberschreitungen in Historischer Perspektive, edited by Marcelo Caruso, Thomas Koinzer, Christine Mayer e Karin Priem, 177-190. Colónia: Böhlau, 2014.

- «Do modo de aprender e de ensinar. Renovação pedagógica e cenários de experimentação da escola graduada (1834-1892)». Phd diss., Lisboa: Faculdade de Psicologia e de Ciências da Educação da Universidade de Lisboa, 2008.

- «O papel dos materiais impressos na difusão do ensino mútuo: duas traduções portuguesas da obra "Sistema Britânico de Educação», de Joseph Lancaster». In Influencias inglesas en la Educación Española e Iberoamericana (1810-2010), edited by José María Hernández Díaz, 629-639. Salamanca: Universidade de Salamanca, 2011.

Markus, Thomas. Buildings \& Power. Freedom and Control in the Origin of Modern Building Types. New York: Routledge, 1993.

Martinho, Miguel, and José Freire da SiLva. «Open Plan Schools in Portugal: Failure or Innovation?». PEB Exchange 12 (2008).

- Novo Diccionario da Lingua Portugueza. Lisboa: Typografia Rollandiana, 1806.

QUERRIEN, Anne. L'école mutuelle: une pédagogie trop efficace?. Paris: les Empêcheurs de penser en rond, 2005.

Ramos do Ó, Jorge, and Luís Miguel CaRvalho. Emergência e circulação do conhecimento psicopedagógico moderno (1880-1960). Estudos comparados Portugal-Brasil. Lisboa: Educa e Unidade de I \& D de Ciências da Educação, 2009.

RoldÁn VERA, Eugenia. "From Monitorial to Graded Schooling in $19^{\text {th }}$ Century Mexico: Politics and Pedagogy in the Definition of Modern Education». In Classroom Struggle. Organizing Elementary School Teaching in the $19^{\text {th }}$ Century, edited by Marcelo Caruso,183-184. Frankfurt: Peter Lang, 2015.

- "Order in the Classroom: the Spanish American Appropriation of the Monitorial System of Education». Paedagogica Historica 41 (6) (2005): 655-675.

- "The Monitorial System of Education and Civic Culture in Early Independent Mexico». Paedagogica Historica 35 (2) (1999).

- Systema Britânico de Educação. Porto: Typ. da Viúva de Alvarez Ribeiro e Filhos, 1823.

- The British System of Education. London: Joseph Lancaster and Longman Co. Paternoster-Row, 1810. 
Tondeur J., E. de Bruyne, M. Van Den Driessche, S. McKenney and D. ZandVLIET. «The physical placement of classroom technology and its influences on educational practices». Cambridge Journal of Education 45 (4) (2015): 537-556.

TYACK, David, and Larry CuBAN. Tinkering toward Utopia: a century of public school reform. Cambridge, MA: Harvard University Press, 1995.

Viña Frago, Antonio, and Agustín Escolano Benito. Currículo, espaço e subjetividade: a arquitetura como programa. Rio de Janeiro: DP\&A, 2001. 